\title{
FEMINICÍDIO COM ADVENTO DA LEI N 13.104/2015
}

\section{ARTIGO ORIGINAL}

CORDEIRO, Alexandre Dos Santos ${ }^{1}$

SILVA, Rubens Alves da ${ }^{2}$

CORDEIRO, Alexandre Dos Santos. SILVA, Rubens Alves da. Feminicídio com advento da Lei $\mathbf{N}^{\circ}$ 13.104/2015. Revista Científica Multidisciplinar Núcleo do Conhecimento. Ano 04, Ed. 09, Vol. 01, pp. 24-43. Setembro de 2019. ISSN: 24480959, Link de acesso: https://www.nucleodoconhecimento.com.br/lei/feminicidio

\section{RESUMO}

O objetivo deste trabalho foi analisar o feminicídio com advento da Lei №. 13.104/2015. A brutalidade contra as mulheres é um dos prodígios mais delatados e de maiores repercussões, visivelmente um problema social, impõe esse fato as sequelas devastadoras da compostura humana e a saúde pública. Conceitua-se como violência a mulher qualquer comportamento, de ação ou blefe, baseada no gênero, que ocasione morte, agravo ou sofrimento físico, sexual ou psicológica à companheira, no domínio público ou privado. Os principais tipos violência a mulheres são: brutalidade sexual, sítio sexual, sítio moral e feminicídio. O crime na sua grande maior parte é aceito no meio doméstico e familiar, aonde o agressor é consecutivamente o favorável parceiro. Uma apreensão entre os homossexuais, transexuais e os congêneres por não se condisserem, pelo fato de não constituírem de forma biológica reconhecida como mulheres. Conjetura-se uma análise das aceitáveis situações impostas em ações decorrentes da tipificação da brutalidade de gênero feminicídio, ao checar diretamente outras seções do Direito, dirige aos

\footnotetext{
${ }^{1}$ Graduando em Direito.

2 Mestre em Direito pela Faculdade de Direito do Sul de Minas, FDSM, Brasil. Professor do curso de Direito do CEULM/ULBRA, Manaus-AM.
} 
aplicadores da nova lei, a desconfiança, e ao tempo, fornecendo materiais para que, nas mãos dos operantes do direito, possam advir detrimentos a moralidade das demais espécies transexuais, homossexuais, lésbicas, travestis, e de tal modo todos os atos cometidos contra a mulher decorrente de espécie ou convívio mesmo que igualitário seja tipificado como feminicídio.

Palavras-chave: feminicídio, brutalidade, mulher, espécie.

\section{INTRODUÇÃO}

O Feminicídio é um delito hediondo no Brasil conforme a lei 13.104/2015 que por sua vez acidentou o código penal e qualificou-o, tal crime é cometido contra mulheres em razão da classe de ser do gênero feminino. Abusa advertir que, excepcionalmente se conforma feminicídio, quando são provadas as originas, que são: ataques físicos ou psicológicos, agressão ou sítio sexual, tortura, mutilação genital, espancamentos entre outra forma de brutalidade que gere a morte de uma mulher, por peculiar questão de gênero. A violência contra mulher comumente possui motivação frívolo. Alcoolismo, drogadição e demandas financeiras são fatores exacerbadores, mas é a macheza declarada no anseio cotidiano de domínio que determina a maioria absoluta. Estas são basais afirmativas dos agressores que veem as mulheres como objetos de seu domínio, e culpando-as pelo acontecido. Sendo uma questão de vivência cultural, virou-se um problema de saúde pública, e crescente comprovação de que a brutalidade doméstica está acompanhada a traumatismos físicos e mentais, direcionando muitas mulheres a procurar invariavelmente serviços de saúde. O acontecimento da violência contra mulher é ecumênico e se atarraca com a própria vida da família. A mulher nasceu para corresponder ao pai e em seguida ao marido, sem ter algum direito, estando impedida de votar e receber o próprio sustento, cumprindo as atividades subordinadas, tais como criar os filhos e preocupar-se com afazeres de casa. Assim ficou domada ao marido, o qual está adjudicado de trabalhar e abastecer o sustento da mulher e dos filhos, praticando assim o poder sobre toda a família (WAISELFISZ, 2016). 


\section{ASPECTO HISTÓRICO DA VIOLÊNCIA DOMÉSTICA E FAMILIAR}

\subsection{VIOLÊNCIA}

Neste argumento, cabe comprovar através dos aspectos históricos a evolução da violência de gênero, apresentando a forma como a mulher era socialmente vista sob um viés patriarcal. Uma vez que a longevidade do abuso sofrido pelas mulheres alongados anos, era um cenário natural e legitimada por meio de um exemplo social imposto atravessadamente do seio familiar e matrimonial pelo clemente moralismo masculino (FONSECA; SOUZA; NASCIMENTO, 2006).

Pautando tal questionamento, arranja-se necessário elucidar que têm conceitos distintos de violência que atingem a mulher, segundo a leitura:

A violência contra a mulher: Contorno característico de violência interpessoal, praticada pelo homem e dirigida à mulher. Violência de gênero: reverência aos papéis igualitários atribuídos a homens e mulheres, alentados por culturas patriarcais, que constituem analogias de violência entre os sexos e não as contestações entre os homens e as mulheres que causam o emprego da violência contra a mulher. Violência Doméstica: advém no âmbito da casa e pode advir entre homens e mulheres, pais e filhos, jovens e idosos. A violência contra a mulher constitui agressão psicológica, física, sexual e em espaço privado ou público, com o indivíduo que a vítima se relaciona ou se relacionou afetuosamente. Em virtude do altivo índice dessa modalidade no espaço privado adveio a ser conhecida como violência doméstica (FONSECA; SOUZA; NASCIMENTO, 2006).

Segundo HELKER (2016), o abuso contra a mulher proporciona uma constituição histórica tenebrosa de preconceito relacionado ao gênero, classe e raça e etnia em suas analogias de poder, assim ganha as mais diversas definições e aprovações, conforme acepção da lei 11.343/06, Maria da Penha, em seu artigo $5^{\circ}$ :

A violência pode ser acatada como qualquer comportamento baseada no gênero, que origine ou passível de originar morte, tortura ou consternação física, sexual ou psicológico à mulher - tantas vezes no 
domínio público e na privada. Várias disposições engajaram na luta contra a violência contra a mulher: A (ONU) Organização das Nações Unidas principiou seus esforços contra esse feitio de brutalidade, na década de 50, com o entusiasmo criador da Comissão de Status da Mulher que constituiu entre os anos de 49 a 62 uma série de ajustados baseados em aprovisionamentos da Carta das Nações Unidas - que asseguram expressamente os direitos análogos adentre homens e mulheres a Declaração Universal dos Direitos Humanos — que assume juntos os direitos e alvedrios humanos necessita ser justapostos outra vez a homens e mulheres, sem altivez de qualquer natureza (HELKER, 2016, p.13).

\subsection{CICLOS DA VIOLÊNCIA}

De acordo com SOUZA (2015), adverte que a sociedade é exorbitantemente venerável e não tem como contradisser, apesar de que nem sempre o patriarcalismo é conveniente.

Nos primórdios da humanidade, os grupos não tinham ciência da analogia entre o sexo e a procriação, constituindo a fertilidade imposta exclusiva da mulher e, precisamente por isso, a mulher tinha um desempenho de evidência na estrutura social. Não existia aqui a ideia da monogamia, constituindo o casamento feito por multidões e, como implicação, os descendentes exclusivamente eram reconhecidos através da linhagem materna (SOUZA, 2015, p.9).

Afirma LINS (2007), que a domesticação dos animais veio o descobrimento da contribuição do homem para a procriação, resultando em uma clara ruptura na história. Esse descobrimento decompôs a relação entre homem e mulher. O homem, finalmente, descobriu seu papel imperioso numa terra em que sua potência foi negada.

\subsection{O CUSTO POUPADO DA VIOLÊNCIA DOMÉSTICA}

A violência doméstica ainda gera despesas econômicas, submergindo geralmente auxílio médico, aparato advocatício responsável e enormes valores de oportunidade. Ter conhecimento desse tipo de correlação auxilia na formatação de políticas públicas que abrandem ao máximo a ocorrência de novos casos (LACAYO, 2017). 
Segundo LACAYO (2017), conforme as consequências e valores da violência, que provocam impactos no indivíduo e aos sobreviventes, perpetradores e outros prejudicados pela violência, assim como no interno da família, do grupo e da sociedade como um todo, causando altos custos para os países conforme citado:

A violência contra mulheres e meninas cobra um custo alto, não só por causa da angústia não visível e do impacto em sua característica de vida e bem-estar, mas ainda pelos valores que o sobrevivente e sua família irão adotar no tratamento de sua saúde (física ou mental), aparentando seu trabalho e finanças. Existe a decorrência disso tudo nas crianças. Uma escolha de dez ensejos e fatores de risco de incapacidade e morte para mulheres entre 15 e 44 anos, estupro e violência doméstica e de gênero, em os seus feitios, acatadas como um caso superior ao câncer, aos acidentes de trânsito, à guerra e à malária. Lesões contidas como fraturas e hemorragias, assim como enfermidades físicas de longa duração (por exemplo: enfermidades gastrointestinais, desordens do sistema nervoso central, dores crônicas). Enfermidades mentais, como depressão, ansiedade, desordens de estresse pós-traumático, ensaio ao suicídio. Problemas sexuais e reprodutivos como contágios por transmissão sexual (incluindo o HIV) e outras enfermidades crônicas; disfunções sexuais; gravidezes forçadas ou não almejadas e abortos indecisos; riscos na saúde materna e na saúde fetal (principalmente em casos de abuso durante a gravidez) (LACAYO, 2017, p. 2-3).

Segundo NOGUEIRA (2017), a falta de agrupamento, dificuldade de tomar decisões, desacertos ou imprevistos e amplo aumento de faltas são os impactos mais expressivos da violência doméstica na vida profissional de milhares de mulheres no Brasil.

\subsection{FORMAS DE VIOLÊNCIA}

De acordo com BIF (2018), os abusos podem ser demonstrados de vários feitios, constituindo em uma grande influência do patriarcado, e são de um feitio de dominação da espécie feminina pelo masculino.

No domínio das relações privadas, a violência contra a mulher é um aspecto fundamental da cultura patriarcal. A violência doméstica é um feitio de violência física ou psíquica desempenhada pelos homens contra as mulheres no âmbito das relações de familiaridade, revelando-se um poder de posse de caráter patriarcal. Podemos pensar na violência doméstica como uma condição de castigo que prática acondicionar o 
comportamento das mulheres e comprovar que não têm o domínio de suas próprias vidas (FERRAZ et al., 2013, p.470).

\subsubsection{VIOLÊNCIA PSICOLÓGICA}

Para GUEDES \& GOMES (2018), a violência psicológica é aquela que abrange a amor-próprio da mulher, deixando-a com a autoestima baixa e levando-a muitas vezes a depressão, normalmente são incumbidas por xingarias, constrangimentos, rebaixamentos, penumbra, chantagens, tudo aquilo que origine suas restrições de ir e vir.

O artigo $7^{\circ}$ inciso II da Lei ํo 11.340/06 dispõe que: II - a violência psicológica, abrangida como qualquer procedimento que the acarrete detrimentos emocionais e descimento da autoestima ou que lhe inutilize e perturbe o pleno incremento ou que dirija degradar ou dominar-se suas ações, condutas, crenças e disposições, mediante ameaça, compressão, afronta, manipulação, isolamento, cuidado constante, acossamento contumaz, ofensa, ultimato, ridicularização, opressão e obstáculo do direito de ir e vir ou alguma outra coisa que lhe origine danos à saúde psicológica e à autodeterminação (BRASIL, 2018).

Segundo MARTINELLI (2018), muitas vezes é complexo reconhecer uma vítima de violência psicológica, podendo-se advertir que diversas mulheres não buscam ajuda e revogam aceitando a forma como são abordadas e não se comovem com tal violência, pois revogam concebendo em suas cabeças que o motivo para tal agressão é ao feitio como ela age, além dos motivos alegados antes, o ciúme acaba consistindo em um amplo vilão, pela feitio como ela se veste, maquiagem, e o agressor concebe em sua cabeça que ela está se lançando para outra pessoa induzindo a cometer a violência.

\subsubsection{VIOLÊNCIA SEXUAL}

BIF (2018), diz que, qualquer ato ou procedimento que leve ao acanhamento ou conhecimento de relação sexual indesejada, mediante estupro, agressão sexual, assédio moral e atentado violento ao pudor são apresentados como violência sexual. 
Esta brutalidade está descrita na Lei $\mathrm{n}^{0}$ 11.340/06 em sua alínea $7^{\circ}$ inciso III. - a brutalidade sexual, alcançada como qualquer conduta que a force a presenciar, a conservar ou a informar de uma relação sexual não almejada, mediante advertência, intimidação, repressão ou uso da coragem; que a leve a revender ou a empregar, de qualquer jeito, a sua sexualidade, que a previna de usar qualquer procedimento contraceptivo ou que a obrigue ao matrimônio, à gravidez, ao aborto ou à vida fácil, mediante coibição, advertência, compro ou manipulação; ou que alcance ou invalide a agilidade de seus direitos sexuais e reprodutores (BRASIL, 2018).

Segundo SOUZA; ROCHA; SIQUEIRA (2019), diz que, a pessoa violentada computa com acolhimento imediato nas redes notórias de saúde, pois perante desta brutalidade os auxiliares são compelidos a darem auxílio a essas mulheres que não deram anuência para terem afinidades sexuais, do mesmo modo sendo, a elas será ministrada a pílula do dia consequente, com coleta de materiais para execução do exame de HIV ou outros tipos de doenças sexualmente transmissíveis, entre outros meios para preservação da sua vida.

\subsubsection{VIOLÊNCIA PATRIMONIAL E MORAL}

Segundo BRASIL (2018), a brutalidade patrimonial está imposta na Lei oํ 11.340/06 em sua alínea $7^{\circ}$ inciso IV.

IV - A brutalidade patrimonial, abrangida como qualquer procedimento que configure fixação, subtração, aniquilamento parcial ou absoluto de seus objetos, aparelhos de trabalho, informações pessoais, bens, apegos e direitos ou soluções econômicas, contendo os destinados a agradar suas obrigações.

Segundo BRASIL (2018) a brutalidade moral é apresentada na Lei № 11.340/06 em sua alínea $7^{\circ}$ inciso $\mathrm{V}$, onde monta que: a brutalidade moral, apreendida como qualquer comportamento que configure calúnia, descrédito ou agravo.

BIF (2018), cita que, a brutalidade que fere a honra de alguma pessoa, ficando todos estes delitos dispostos no Código Penal Brasileiro. 
Caluniar é atribuir a alguém de um delito "imputando-lhe deslealmente o fato definido como delito", podendo-se advertir que a injúria aparece quando a vitima tem a sua dignidade ofendida, e difamada significando imputar-se ao fato ofensivo à reputação de alguém" (OPAS \& BRASIL, 2018).

\subsection{PERFIL DO ABUSADOR E DA VÍTIMA}

MADUREIRA et. Al. (2014), afirma que, a aspereza da brutalidade perpetrada contra as mulheres é demonstrada nos registros de óbitos de mulheres em todo o planeta.

Segundo SOUZA (2015), o agravamento demonstrado, em uma enorme parcela de mulheres, que vivenciam o abuso, opta em continuar no convívio com o agressor e, desse modo, a precaução e o cuidado necessitam abranger não exclusivamente as vítimas, mas além disso os cônjuges autores dessa violência, com aceites a atuar em prol do cuidado de sua vitimização.

Para DANTAS \& LENHARO (2018), o abuso em mulheres é cometida por adolescentes e até idosos, mas na maioria dos episódios os atacantes são homens entre 25 e 30 anos, adicionando-se a isso, outro maior problema pertinente a estas agressões é a escolaridade, distinguindo que $47,6 \%$ dos homens que incumbem esta agressão nem sequer acabaram a escolaridade, embora, aposentados ou companheiros desempregados aumentam em até duas vezes as oportunidades de cometer estes tipos de agressões.

\section{O FEMINICÍDIO E AS MEDIDAS DE PROTEÇÃO}

Cabe advertir, relatos de doutrinadores, sobre o implemento das medidas protetivas é uma das basais diretrizes indispensáveis para a efetividade das medidas de proteção, na prevenção do feminicídio. Aclarando a necessidade que tenha vistoria da execução das medidas protetivas como o nexo das normas, judiciário e policial. Profissionais envolvidos na área de medidas protetivas distinguem a obrigação de integração tecnológica entre as leis da polícia e do judiciário. Para que se contenha flagrante de crime de inadimplência da medida protetiva, de que, é imprescindível que a medida 
protetiva permaneça vigorante, e que o autor do fato esteja notificado para que se haja feitio de um crime de inadimplência. Outro fator de maior relevância é que não haverá um policial para cada vítima. É admirável que a mulher, seus familiares ou vizinhos possam comunicar prontamente que o homem está desobedecendo a medida e com isso tendo a cautela do feminicídio com a prisão do agressor e praticante de abuso contra mulher (SANTOS, M.; ARAÚJO; SANTOS, J., 2015).

\subsubsection{TIPOS DE FEMINICÍDIO}

Para HOCHMULLER (2014), esta classe pode ser subdividida em dois grupos: feminicídio não familiares e feminicídio sexuais: segundo a vítima tenha sido ou não abusada sexualmente, algo muito comum nesta classe. Pondere que feminicídio sexuais são um feitio de terrorismo que robustece a dominância masculina e presta a todas as mulheres o efeito de insegurança consecutiva.

Segundo RODRIGUES (2015), o feminicídio íntimos: são atos cometidos por cônjuges com os quais a vítima possui ou teve uma relação íntima, doméstica, de convívio ou afins. Abrange-se nesta classe os crimes atentados por parceiros somente sexuais ou por aqueles com quem o paciente tem ou conteve outras analogias interpessoais, tais como homens, companheiros ou namorados.

De acordo com SOUZA (2015) diz que, o feminicídio não íntimos: são aqueles atentados por homens com os quais a vítima não tem relações íntimas, familiares ou de convívio, mas com os quais era ligada por relações de certeza, hierarquia ou afeição, entre patrão e ajudante doméstica, pessoais ou ainda colegas de trabalho.

Afirma RODRIGUES (2015), que salienta que o feminicídio por atrelamento: acontecem quando uma mulher interfere para impedir o homicídio de outra mulher e, no procedimento, acaba ainda se tornando uma vítima inevitável. Por seu caráter, dispensável a existência de junções entre o agente e a vítima para diferenciá-lo, aos quais podem ser até ignorados. 


\subsection{DAS MEDIDAS AGREGADAS DE PREVENÇÃO}

No que diz reverência às regulares prevenções sobre o feminicídio é acolher as medidas protetivas de urgência do domínio do Direito das Famílias sejam promovidas pela vítima perante o comando policial. A pessoa, ao registrar o fato do exercício de violência doméstica, pode agenciar o afastamento de corpos, mantimentos, vedação de $o$ atacante abeirar-se da vítima e de seus familiares ou que seja ele reprimido de ir a determinados lugares (DIAS, 2007).

Art. 22. Observada o exercício de brutalidade doméstica e profundamente contra a mulher, nas adjacências desta Lei, o juiz poderá cultivar de imediato, ao atacante, em adjacente ou separadamente (BRASIL, 2018).

Segundo BRASIL (2018), as lógicas medidas protetivas de urgência, entre outras:

I - Interrupção da posse ou intimidação da presença de armas, com acessão ao órgão competente, nas adjacências de pacto com a Lei no 10.826, imposta em 22 dezembro de 2003;

II - Abdução do lar, domicílio ou lugar de coexistência com a vítima; III - impedimento de verificadas condutas, dentre as quais: a) aproximação da vítima, de seus íntimos e das testemunhas, adsorvendo o limite mínimo de alcance entre estes e o atacante; b) contato com a agravada, seus familiares e testemunhas por algum meio de comunicação; c) relação de determinados sítios a fim de conservar a probidade física e psicológica da insultada;

IV - Exceção ou interrupção de visitas aos condicionados de segundo grau, ouvida ao grupo de recepção multidisciplinar ou emprego equivalente;

V - Cota de alimentos provisionais ou temporários.

$\S 1^{\circ}$ As competentes medidas protetivas rápidas poderão ser concedidas de imediato, involuntariamente de julgamento das partes e de aparecimento do Ministério Público, necessitando este ser imediatamente noticiado. 
$\S 2^{2}$ As medidas protetivas rápidas serão justapostas independente ou cumulativamente, e poderão ser trocadas a algum tempo por outras de máxima eficácia, consecutivamente que os direitos reconhecidos nesta Lei forem advertidos ou infringidos.

§ 3ํ Poderá o magistrado, a solicitação do Ministério Público ou a rogativa da ofendida, outorgar inovações medidas protetivas de urgência ou rever aquelas já outorgadas, se abranger imprescindível ao amparo da injuriada, de seus íntimos e de seu patrimônio, ouvido ao Ministério Público (BRASIL, 2018).

As medidas protetivas que juramentam o agressor constam no artigo 22 da lei 11.340/06 esta elenca medidas protetivas que obrigam o agressor, voltadas diretamente ao sujeito ativo da violência doméstica, impondoIhe obrigações e restrições, tais medidas restringem determinados direitos do agressor a fim de proteger a vítima, impondo-lhe comportamento omissivo, cuja conduta que injuriar a ordem de abstenção tipificará então o crime de indisciplina à ordem judicial, com prevenção expressa no artigo 359 do Código Penal, com probabilidade de prisão em evidente (PORTO, 2014, p.82).

Com analogia às medidas protetivas de urgência muito ainda a mulher em circunstância de violência ajudante doméstica e familiar seja a elementar destinatária das medidas protetivas, várias delas dirigem-se, aos familiares, apontadas a mulher, nenhuma possuindo natureza criminal, podendo de modo inclusivo, serem cumuladas ou não, dependendo da complexidade e distintivos do caso palpável (PORTO, 2014).

O artigo 23 da lei que dispõe sobre as medidas protetivas com afinidade à ofendida, segundo BIANCHINI (2014), o Art. 23. poderá o juiz, quando imprescindível, sem prejuízo de outras medidas que incluem:

I - Dirigir-se à ofendida e seus condicionados à programa oficial ou comunitário de abrigo ou de acolhimento;

II - Originar a recondução da injuriada e a de seus subordinados ao relativo domicílio, após afugentamento do agressor; 
III - decidir a alienação da injuriada do lar, sem detrimento dos direitos concernentes a bens, guarda dos filhos e alimentações;

IV - Originar o afastamento de corpos.

Segundo PORTO (2014), preceitua a alínea 24 da própria lei, fixar-se o Art. 24. Para o amparo patrimonial dos bens da sociedade matrimonial ou daqueles de domínio particular da mulher, o juiz poderá originar, liminarmente, as consequentes medidas, entre outras:

I - Devolução de bens indevidamente diminuídos pelo agressor à injuriada;

II - Suspensão provisória para a celebração de atos e combinados de compra e venda e locação de atributo em comum, salvo explanada autorização judicial;

III - interrupção das incumbências conferidas pela injuriada ao agressor;

IV - Pagamento de fiança provisória, mediante depósito judicial, por perdas e prejuízos materiais decorrentes da prática de brutalidade doméstica e familiar contra a injuriada.

Parágrafo único: Precisará o juiz oficiar ao cartório adeque para os fins preditos nos incisos II e III dessa alínea.

\subsection{O FEMINICÍDIO NO ORDENAMENTO JURÍDICO-PENAL BRASILEIRO}

Afirma BRASIL (2018), que o Feminicídio no ordenamento jurídico-penal brasileiro se condiz em conformidade com os órgãos de proteção estabelecidos pelos Direitos Humanos no art. 226, inciso $\S 8^{\circ}$ da Carta Magna do ano de 1988.

No entanto o feminicídio no ordenamento jurídico-penal brasileiro é editado no dia 07 de agosto de 2006, pela lei $n$ ำ11.340, que regulamenta mecanismos para abster-se e precatar a brutalidade doméstica e íntima contra a mulher e preparando a educação de juizados de agressão doméstica e íntima contra a mulher, bem como formando medidas de subsídio e proteção às mulheres em posições de brutalidade doméstica e 
íntima. A Lei Maria da Penha tem uma circunscrição de grande proteção, envolve um dígito maior de benefícios juridicamente tutelados, qualquer atuação ou supressão que possa the motivar a morte; detrimento; consternação física que agrave sua integridade ou seu bem-estar corporal; brutalidade psicológica passível de avaria emocional ou lesione, sua altivez; violência sexual; patrimonial e moral quanto a calúnia, descrédito ou injuria (SANTOS, M.; ARAÚJO; SANTOS, J., 2015).

\section{LEI 13.104/2015 - FEMINICÍDIO}

Segundo MEDEIROS (2018), diz que, a concepção da lei 13.104/2015 de 9 de março de 2015, adicionou a alínea $121, \S 2^{\circ}$ do Código Penal, o inciso VI. Com o original inciso o legislador vira hediondo o crime feito contra as mulheres por ensejo da espécie de sexo feminino.

Afirma BITTENCOURTH (2018), que as graves violações quando aos aprumados das mulheres, bem como o blefe estatal é designado a uma tipificação ao Código Penal Brasileiro, com a qualificação de feminicídio, sendo ele deliberado ao termo feminicídio que é definido segundo a Comissão Parlamentar Mista de Inquérito a propósito da Brutalidade Contra a Mulher. O Feminicídio é a veemência última de autoridade da mulher pelo homem: O mando da vida e da morte. Ele se manifestada com afirmação incondicional de posse, idêntico a mulher a um objeto, assim como cometido por companheiro ou ex-parceiro, como subjugação do contubérnio e sexualidade da mulher, por elemento da violência sexual adjunta ao assassinato, como destruição do contubérnio da mulher, pela mutilação dou desfiguração de seu coro, reprimindo a mortificação ou tratamento cruel e ofensivo.

Segundo PORTO (2014), o significado de brutalidade doméstica para diferenciar-se o crime de Feminicídio é determinada pela lei Maria da Penha, lei 11.340/06, em sua alínea 5‥ Esta ordena que: Alguma ação ou deleção baseada no modelo que the ocasione morte, lesão, dor física, sexual ou psicológica e agravo moral ou patrimonial, no domínio da unidade empregada, da família ou em alguma relação íntima de apego, involuntariamente de orientação sexual. 
Afirma DIAS (2007), que observa a inspiração do Crime de Feminicídio da alínea 121, inciso VI, do Código Penal, o procedimento advém a ser considerado delito hediondo, incidindo a constar no rol daqueles listados na lei 8.072/90, com aflição de 12 a 30 anos.

\subsection{AS ALTERAÇÕES FEITAS PELA LEI 13.104/2015 - FEMINICÍDIO}

De acordo com GUEDES \& GOMES (2018) alegam que, dia 09 de março de 2015 a Presidente Dilma Rousseff determinou a Lei do Feminicídio, legislação esta que decompõe a alínea nำ121 do Código Penal Brasileiro, envolvendo o feminicídio como episódio qualificador e no rol dos delitos hediondos. É extraordinário nos atentarmos para não incumbir o desacerto de dizer que o feminicídio é um novo crime. A mencionada lei não é um cujo penal e sim uma qualificadora, o subordinado crime que ficamos discutindo é o homicídio e o feminicídio nasce na lista de episódios qualificados deste tipo de delinquência. Sobre tal altivez de nomenclatura, destaca-se além disso que o marco feminicídio é usual para quando uma mulher é chacinada, já a adjacência feminicídio é a morte de uma mulher por ensejos de gênero ou pelo desprezo ou discernimento à categoria de mulher que é qualificadora de assassinato.

Segundo SANTOS, M.; ARAÚJO; SANTOS, J.; (2015), para o Direito Penal Brasileiro, o Feminicídio que é o aniquilamento de pessoas do sexo feminino, é um delito que não computa com nem uma vinculação com a brutalidade doméstica ou em ensejo de discernimento à condição de mulher, juridicamente irrelevante.

O feminicídio pode ser categórico como uma qualificadora do delito de homicídio originado pela odiosidade contra as mulheres, distinto por conjunturas privativas em que o pertencimento da mulher ao sexo feminino é essencial no tirocínio do delito.

Art. $1^{\circ}$ a alínea 121 do Decreto da Lei no 2.848, de 7 de dezembro de 1940 referido ao Código Penal, no Brasil de 1940, incide a vigorar com a consequente redação:

Homicídio simples: alínea 121;

Homicídio qualificado: inciso $\S 2^{\circ}$; 
O Feminicídio: VI - contra a mulher por ensejos da espécie de sexo feminino;

$\S$ 2 - A Ponderasse que há ensejos de categoria de sexo feminino como o crime que envolve: I - brutalidade doméstica e familiar; II - deprecio ou discernimento à classe de mulher.

O seguinte fato é a alínea $2^{\circ}$ e a alínea $1^{\circ}$ da Lei ํㅜ 8.072 , sancionada em 25 de julho de 1990, a vigorar com a consequente alteração: Art. 1ㅇ I - homicídio (art. 121), como praticado em velocidade típica da coligação de extermínio, ainda que incumbido por um só delegado, e homicídio classificado na alínea 121, nos incisos $\S 2^{\circ}$, I, II, III, IV, V e VI. (BRASIL, 2018).

Segundo GAMA (2015), as causas apreciadas que elencam a categoria de sexo feminino, conforme o legislador são: 1) brutalidade doméstica e íntima; 2) desprezo ou discernimento à classe de mulher. Diz BRASIL (2018), que para se colocar que é brutalidade doméstica e íntima, podemos nos prevalecer-se da alínea $5^{\circ}$ da Lei 11.340/2006:

Alínea $5^{0}$ para as decorrências desta Lei conforme a brutalidade doméstica e íntima contra a mulher alguma ação ou eliminação fundamentada no modelo que the cause morte, detrimento, angústia física, sexual ou psicológico e injúria ética ou patrimonial:

I - No domínio da unidade doméstica, abrangida como o espaço de conversação durável de pessoas, com ou sem conexão familiar, até mesmo as esporadicamente reunidas;

II - No domínio da família, abrangida como a conformidade formada por pessoas que são ou se avaliam aparentados, ligados por laços naturais, por cognação ou por vontade explanada;

III - em alguma relação familiar de afeição, ao atacante habite ou tenha vivido com a afrontada, involuntariamente de coabitação (BRASIL, 2018). 
Para que se anua o feminicídio, basta que haja exclusivamente uma das hipóteses prevenidas no $\S 2^{\circ}$-A alínea 121 do Código Penal Brasileiro, brutalidade doméstica e íntima, ou deprecio ou discriminação à categoria de mulher.

Afirma BIANCHINI (2014), que a Lei do Feminicídio ainda estipula uma majorante, onde junta as penas nas coisas específicas do parágrafo $7^{\circ}$.

$\S 7^{\circ}$ a pena do feminicídio é justaposta de $1 / 3$ em até a $1 / 2$ se o crime for perpetrado:

I - Durante a gestação os três meses posteriores ao nascimento;

II - Contra pessoa mínima de catorze anos e maior de sessenta anos ou com insuficiência;

III - na compleição de descendente ou de antepassado da vítima.

\section{CONCLUSÃO}

A Lei Maria da Penha é um modelo de obstinação, garantia e altivez de sensível da natureza humana. Adverti que foi conciso medidas até de natureza internacional e organiza um ampliador ineficaz, cotejando o índice dos períodos antes e depois do vigor da Lei do feminicídio no. 13.104/2015. O atual artigo retratou os pontos mais extraordinários da qualificadora do feminicídio. Foi concretizado, uma arremetida histórica da brutalidade de gênero, bem como da efetividade em se descrever o Direito Penal ao afrontar este triste fato que muitas mulheres convivem, ou não sobrevivem. As leis brasileiras são evidentes o poder simbólico que o Direito Penal possui e que de não abusará puramente a criação do feminicídio sem a envolvimento do Poder Público e da população em um todo, em conclusão, o desígnio principal é a anticoncepção, e a eficácia do início da compostura da pessoa humana, declivando de todo o ordenamento jurídico brasileiro. 


\section{REFERÊNCIAS}

BIANCHINI, A. Lei no 11.340/2006 de Maria da Penha. Aspectos Assistenciais:

Protetivos e Criminais da brutalidade de gênero. 2. ed. São Paulo: Saraiva, 2014. Acesso em: 12 ago. 2019.

BIF, R. B. O Delito de Feminicídio e o Combate à Violência Contra as Mulheres. Trabalho de conclusão do curso em Bacharel em Direito: Araranguá - SC, 2018. Acesso em: 12 ago. 2019.

BITTENCOURTH, L. de O; SILVA, L. Z; ABREU, I. de S. Feminicídio No Brasil: A Cultura de Matar Mulheres. Internet: Site Multivix, 2018. Acesso em: 09 ago. 2019.

BRASIL. Casa Civil. Presidência da República. Assuntos Jurídicos. Decreto-Lei no 2.848, sancionada em 07 de dezembro de 1940. Senado Federal: Brasília, 2018. Acesso em: 09 ago. 2019.

DANTAS, C.; LENHARO, M. Estudos sobre o atacante ajudam a condenar a brutalidade contra a mulher. Psicologias do Brasil, 2018. Acesso em: 09 ago. 2019.

DIAS, M. B. A lei Maria da Penha: estabelecida pela Lei o․ 11.340/2006. Revista dos Tribunais. São Paulo - SP, 2007. Acesso em: 12 ago. 2019.

FERRAZ, et. Al. Manual dos direitos da mulher. p. 470 São Paulo: Saraiva. 2013. Acesso em: 13 ago. 2019.

FONSECA, P. M.; SOUZA, L.; NASCIMENTO T. Brutalidade doméstica contra a mulher e seus Resultados psicológicos. Salvador (BA): EBM, 2006. Acesso em: 14 ago. 2019.

GAMA, P. G. G. da. Lei Maria da Penha e seus Aspectos Sociais, Implicação e Efetividade com Afinidade ao Feminicídio. Rio grande do Sul: Santa Cruz do Sul: UNISC, 2015. Acesso em: 20 ago. 2019. 
GUEDES, B. K. S.; GOMES, F. K. S. Violência contra a mulher. Faculdades Cearenses, 2018. Acesso em: 11 ago. 2019.

HELKER, M. Da Agressão Doméstica Fatal Contra a Mulher. pag. 13. UNIR. Cacoal - RO, 2016. Acesso em: 21 ago. 2019.

HOCHMULLER, M. de A. Reflexos da Brutalidade de Gênero na Corte Interamericana de Direitos Humanos. UFSC. Florianópolis- SC, 2014. Acesso em: 17 ago. 2019.

LACAYO, V. Os custos sociais e econômicos da violência de gênero. p. 2-3. Internet: Site Rel Uita, 2017. Acesso em: 12 ago. 2019.

LINS, R. N. A Cama na Varanda: arejando nossas ideias a respeito de amor e sexo: novas tendências. Rio de Janeiro: Best Seller, 2007. Acesso em: 12 ago. 2019.

MADUREIRA, et. al. Perfil de cônjuges autores de brutalidade contra mulheres apreendidos em flagrante: apoios para o enfrentamento. Escritora Anna Nery, 2014. Acesso em: 12 ago. 2019.

MARTINELLI, A. Violência psicológica é a feitio mais individual de agressão contra a mulher: Huff Post Brasil, 2018. Acesso em: 12 ago. 2019.

MEDEIROS, L. CF 2018 e a brutalidade contra a mulher: a expressão mais patética da desigualdade de gênero no brasil. Portal das Cebs, 2018. Acesso em: 13 ago.2019.

NOGUEIRA, E. Brutalidade contra a mulher origina prejuízo de $\mathbf{R} \$ \mathbf{1}$ bilhão para reserva brasileira. Agência Brasil, 2017. Acesso em: 13 ago. 2019.

OPAS BRASIL. Violência. Internet: Site PAHO, 2018. Acesso em: 13 ago. 2019.

PORTO, P. R. F. Brutalidade Doméstica e Íntima Conta a Mulher: Lei 11.340/06 em análises crítica e sistêmica. 3. ed. p.82. Porto Alegre, 2014. Acesso em: 18 ago. 2019. 
RODRIGUES, L. Pesquisa traça perfil de vítimas de brutalidade doméstica: em comum, inferior escolaridade, emprego e idade de 31 e 40 anos. Diário de Pernambuco, 2015. Acesso em: 14 ago. 2019.

SOUZA, C. D. P. de. Aspectos Ressaltantes do Feminicídio na Legislação Brasileira. Curso de Preparo à Magistratura Núcleo Curitiba. pag. 9. EMEPR. Curitiba - PR, 2015. Acesso: 20 ago. 2019.

SOUZA, K. O.; ROCHA, L. G.; SIQUEIRA, T. P. Cultura da brutalidade e o Feminicídio, uma saída ou um apanágio. UNESC. Cacoal (RO), 2019. Acesso em: 16 ago. 2019.

WAISELFISZ, J. J. Homicídio de Mulheres no Brasil. Mapa da Brutalidade. Brasília -DF, 2016. Acesso em: 15 ago. 2019.

Enviado: Agosto, 2019.

Aprovado: Setembro, 2019. 